National Science Foundation Graduate Fellowship and Grant ATM-9900929

\title{
SATELLITE AND RADAR SURVEY OF MESOSCALE CONVECTIVE SYSTEM DEVELOPMENT
}

by Israel L. Jirak

William R. Cotton, P.I.

\section{Department of \\ Atmospheric Science}




\title{
SATELLITE AND RADAR SURVEY OF MESOSCALE CONVECTIVE SYSTEM DEVELOPMENT
}

\author{
by \\ Israel L. Jirak \\ Department of Atmospheric Science \\ Colorado State University \\ Fort Collins, Colorado 80523
}

\author{
Research Supported by \\ National Science Foundation \\ under a Graduate Fellowship and Grant ATM-9900929
}

June 27,2002

Atmospheric Science Paper No. 727 


\section{ABSTRACT \\ SATELLITE AND RADAR SURVEY OF MESOSCALE CONVECTIVE SYSTEM DEVELOPMENT}

An investigation of mesoscale convective systems (MCSs) during the warm seasons (April-August) of 1996-1998 is presented. The MCSs were initially identified and classified by infrared satellite imagery. A satellite classification scheme encompassing MCSs of a wide variety of shapes and sizes is introduced. The classes include mesoscale convective complexes (MCCs), persistent elongated convective systems (PECSs), meso- $\beta$ MCCs (MRMCCs), and meso- $\beta$ PECSs (MBPECSs). Definitions, basic characteristics, and examples are provided for each. In addition, the development of each of the systems was analyzed using 2-km national composite radar reflectivity data. A three-level classification process describing MCS development is identified. These levels include determining the presence of stratiform precipitation, arrangement of convective cells, and interaction of convective clusters . Each level of the classification process is described and compared in detail, along with examples.

The environment in which each MCS developed was determined from the standard National Weather Service upper-air network. Additionally, the severe weather 
reports were logged for each system. The findings of these data are discussed in context of the present classification schemes. Furthermore, composite analyses of the satellite lifecycle and precipitation lifecycle are presented.

Israel L. Jirak

Department of Atmospheric Science Colorado State University

Fort Collins, Colorado 80523

Summer 2002 


\section{ACKNOWLEDGEMENTS}

I am grateful to Colorado State University and the Department of Atmospheric Science for providing an educational environment that allowed myself to pursue research in the field of atmospheric science. First of all, I would like to thank my advisor, Dr. William R. Cotton, for his guidance on my research. In addition, I would like to recognize Dr. Steven A. Rutledge and Dr. Jorge A. Ramírez for serving on my committee.

I am truly indebted to Ray McAnelly for all of the help and advice that he offered. Without his expertise, the research presented in this thesis would surely not be the same and certainly would have taken longer to finish. Furthermore, I would like to thank the remaining members of the Cotton group for all of the assistance and support that they have provided.

Infrared satellite data and radar composite data were provided by the Global Hydrology Resource Center. This research was supported by a National Science Foundation (NSF) Graduate Fellowship as well as NSF grant ATM-9900929.

Finally, I would like to thank my family, and especially my wife, Hannah, for her love, support, caring, and understanding in carrying me through this research. 


\section{TABLE OF CONTENTS}

1 Introduction $\quad 1$

2 Background 5

2.1 Satellite classification of MCSs . . . . . . . . . . . . . . 6

2.2 Radar classification of MCSs . . . . . . . . . . . . 8

2.2.1 Radar classification by organization . . . . . . . . . . . . . . . . . . . .

2.2.2 Radar classification by development . . . . . . . . . . . 12

3 Data and methods of analysis $\quad 17$

3.1 Study area and period . . . . . . . . . . . . . . . 17

3.2 Satellite data . . . . . . . . . . . . . . . . . . . 19

3.2 .1 Dataset information . . . . . . . . . . . . . . . 19

3.2 .2 Satellite analysis . . . . . . . . . . . . . . . . . . . . . . . . . 19

3.3 Radar data . . . . . . . . . . . . . . . . . 21

3.3 .1 Dataset information . . . . . . . . . . . . . . 22

3.3 .2 Radar analysis . . . . . . . . . . . . . . . . . 22

3.4 Sounding data and severe weather reports . . . . . . . . . 24

4 Satellite classification of MCSs $\quad 27$

4.1 Definition of classes . . . . . . . . . . . . . . . 27

4.2 Basic characteristics . . . . . . . . . . . . . . . . 30

4.3 Examples of classes . . . . . . . . . . . . . . . . 34

5 Radar classification of MCSs $\quad 39$

5.1 Classification by organization . . . . . . . . . . . . 39

5.2 Classification by development . . . . . . . . . . . . . . 43

5.2 .1 Definition of classes . . . . . . . . . . . . . . . 44

5.2 .2 Basic characteristics ..................... 48

5.2 .3 Examples of classes . . . . . . . . . . . . . . . 54 
6 MCS environment and severe weather $\quad 61$

6.1 Average properties of soundings . . . . . . . . . . . . 61

6.2 Properties of average soundings . . . . . . . . . . . 67

6.3 Severe weather reports . . . . . . . . . . . . . . . 69

7 MCS composite results $\quad 81$

7.1 MCS tracks . . . . . . . . . . . . . . . . 81

7.2 MCS satellite lifecycle . . . . . . . . . . . . . . . 90

7.3 MCS radar lifecycle . . . . . . . . . . . . . . . 96

8 Summary and conclusions $\quad 107$

8.1 Summary . . . . . . . . . . . . . . . . 107

8.2 Conclusions . . . . . . . . . . . . . . . 107

8.3 Suggestions for future research . . . . . . . . . . . . . . 111

$\begin{array}{ll}\text { A Sounding Indices } & 113\end{array}$ 


\section{LIST OF FIGURES}

2.1 Symmetric and asymmetric TS MCS (Houze et al. 1990) . . . . . . . . 10

2.2 Swiss MCS archetypes (Schiesser et al. 1995) . . . . . . . . . . . . 10

2.3 Linear MCS archetypes (Parker and Johnson 2000) . . . . . . . . . 11

2.4 Classification of squall line development (Bluestein and Jain 1985) . . . 13

2.5 Classification of mesoscale convective patterns (Blanchard 1990) . . . . 14

2.6 Paths to asymmetric TS structure (Loehrer and Johnson 1995) . . . . . 15

3.1 Geographical area of study . . . . . . . . . . . . . . . . . 18

3.2 Example of an MCC plot of satellite characteristics . . . . . . . . . 21

3.3 Example of an MCC plot of radar characteristics . . . . . . . . . . 24

4.1 Distribution of MCSs as a function of size . . . . . . . . . . . 33

4.2 Distribution of MCSs as a function of initiation time, time of maximum extent, and termination time. . . . . . . . . . . 34

4.3 Infrared satellite images of a MCC example . . . . . . . . . . . . 35

4.4 Infrared satellite images of a PECS example . . . . . . . . . . 36

4.5 Infrared satellite images of a $\mathrm{M} \beta \mathrm{MCC}$ example . . . . . . . . . . . 37

4.6 Infrared satellite images of a M $\beta$ PECS example . . . . . . . . . . . 38

5.1 Radar reflectivity examples of radar organization categories . . . . . . 44

5.2 Classification of MCS development . . . . . . . . . . . 47

5.3 Radar images of an areal merger example . . . . . . . . . . . . . 55

5.4 Radar images of a combination merger example . . . . . . . . . . . . 56

5.5 Radar images of an areal growth example . . . . . . . . . . 57

5.6 Radar images of a line merger example . . . . . . . . . . . . 58

5.7 Radar images of an embedded areal merger example . . . . . . . . . 59

5.8 Radar images of an arcal isolated example . . . . . . . . . . . . 60 
6.1 Scatter plot of maximum area against duration. . . . . . . . . 63

6.2 Scatter plot of maximum area against total totals index. . . . . . . 64

6.3 Scatter plot of maximum area against precipitable water. . . . . . . . 65

6.4 Mean sounding for all systems. . . . . . . . . . . . . . . . 68

6.5 Mean sounding for MCCs. . . . . . . . . . . . . . 69

6.6 Mean sounding for PECSs. . . . . . . . . . . . . . . 71

6.7 Mean sounding for M $\beta$ MCCs. . . . . . . . . . . . . . 72

6.8 Mean sounding for MBPECSs. . . . . . . . . . . . . . . 74

6.9 Mean sounding for embedded systems. . . . . . . . . . . . . . . 75

6.10 Mean sounding for systems that were not embedded. . . . . . . . . . 75

6.11 Mean sounding for areal systems. . . . . . . . . . . . . . 76

6.12 Mean sounding for line systems. . . . . . . . . . . . . . 76

6.13 Mean sounding for combination systems. . . . . . . . . . . 77

6.14 Mean sounding for merger systems. . . . . . . . . . . . . 77

6.15 Mean sounding for growth systems. . . . . . . . . . . . . 78

6.16 Mean sounding for isolated systems. . . . . . . . . . . . . 78

6.17 Mean sounding for unclassifiable systems. . . . . . . . . . . . . 79

7.1 Plot of MCS tracks for all systems. . . . . . . . . . . . . 83

7.2 Plot of MCC tracks. . . . . . . . . . . . . . . 83

7.3 Plot of PECS tracks. . . . . . . . . . . . . . . . . 84

7.4 Plot of $\mathrm{M} \beta \mathrm{MCC}$ tracks. . . . . . . . . . . . . . . . 84

7.5 Plot of M $\beta$ PECS tracks. . . . . . . . . . . . . . 85

7.6 Plot of MCS tracks for embedded systems. . . . . . . . . . . . . 86

7.7 Plot of MCS tracks for systems that were not embedded. . . . . . . . 86

7.8 Plot of MCS tracks for areal systems. . . . . . . . . . . . . 87

7.9 Plot of MCS tracks for line systems. . . . . . . . . . . . 87

7.10 Plot of MCS tracks for combination systems. . . . . . . . . . . . . 88

7.11 Plot of MCS tracks for merger systems. . . . . . . . . . . . . . . 88

7.12 Plot of MCS tracks for growth systems. . . . . . . . . . . . . . . 89

7.13 Plot of MCS tracks for isolated systems. . . . . . . . . . . . . . 89

7.14 Infrared satellite lifecycle composite for all systems. . . . . . . . . . . 91

7.15 Infrared satellite lifecycle composite for MCCs. . . . . . . . . . . . 91 
7.16 Infrared satellite lifecycle composite for PECSs. . . . . . . . . . . . 92

7.17 Infrared satellite lifecycle composite for M $\beta$ MCCs. . . . . . . . . . 92

7.18 Infrared satellite lifecycle composite for M $\beta$ PECSs. . . . . . . . . . . 92

7.19 Infrared satellite lifecycle composite for embedded systems. . . . . . . 93

7.20 Infrared satellite lifecycle composite for systems that were not embedded. 93

7.21 Infrared satellite lifecycle composite for areal systems. . . . . . . . . 93

7.22 Infrared satellite lifecycle composite for line systems. . . . . . . . . 94

7.23 Infrared satellite lifecycle composite for combination systems. . . . . . 94

7.24 Infrared satellite lifecycle composite for merger systems. . . . . . . . 94

7.25 Infrared satellite lifecycle composite for growth systems. . . . . . . 95

7.26 Infrared satellite lifecycle composite for isolated systems. . . . . . . . 95

7.27 Radar lifecycle composite for all systems. . . . . . . . . . . . . 97

7.28 Radar lifecycle composite for MCCs. . . . . . . . . . . . . . 97

7.29 Radar lifecycle composite for PECSs. . . . . . . . . . . . . . 98

7.30 Radar lifecycle composite for MBMCCs. . . . . . . . . . . . 98

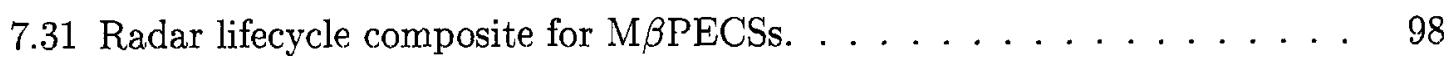

7.32 Radar lifecycle composite for embedded systems. . . . . . . . . . . 99

7.33 Radar lifecycle composite for systems that were not embedded. . . . . . 99

7.34 Radar lifecycle composite for areal systems. . . . . . . . . . . . . . 99

7.35 Radar lifecycle composite for line systems. . . . . . . . . . . . 100

7.36 Radar lifecycle composite for combination systems. . . . . . . . . 100

7.37 Radar lifecycle composite for merger systems. . . . . . . . . . . 100

7.38 Radar lifecycle composite for growth systems. . . . . . . . . . . . 101

7.39 Radar lifecycle composite for isolated systems. . . . . . . . . . . . 101 


\section{LIST OF TABLES}

2.1 Definition of mesoscale convective complex (MCC) (Maddox 2980). . . 7

2.2 Modified MCC definition (Augustine and Howard 1988) . . . . . . . . . 8

4.1 MCS definitions based upon analysis of infrared satellite data . . . . . 29

4.2 Distribution of MCS type (1996-1998) . . . . . . . . . . . . 31

4.3 Statistics for each MCS type: means and (standard deviations). . . . . . 32

5.1 Distribution of radar organization by MCS type (1996-1998) . . . . . . . 41

5.2 Distribution of radar organization by month (1996-1998) . . . . . . . . 42

5.3 Statistics for each radar organization type: means and (standard deviations). 43

5.4 Distribution of MCS development by satellite classification. . . . . . . . 49

5.5 Distribution of MCS development by satellite classification broken into the three levels of the classification process. . . . . . . . . . 50

5.6 Distribution of MCS development by month broken into the three levels of the classification process. . . . . . . . . . . 52

5.7 Statistics for each radar development level: means and (standard deviations). 53

6.1 Average properties of soundings for the entire MCS sample. Means and (standard deviations). . . . . . . . . . . . . . 6 62

6.2 Sounding properties for each MCS satellite classification: means and (standard deviations). . . . . . . . . . . . . . . 65

6.3 Sounding properties for each MCS radar classification: means and (standard deviations). . . . . . . . . . . . . . . 66 66

6.4 Properties of average soundings for each satellite classification. . . . . . 67

6.5 Properties of average soundings for each radar classification. . . . . . . 70

6.6 Number of severe weather reports for each MCS satellite classification. . 73

6.7 Number of severe weather reports per MCS for each satellite classification. 73

6.8 Number of severe weather reports for each radar classification. . . . . . . 79

6.9 Number of severe weather reports per MCS for each radar clasisification. $\quad 80$ 
7.1 Total precipitation mass, average motion, and percentage of convective precipitation for the composite of each MCS satellite classification. . . 103

7.2 Total precipitation mass, average motion, and percentage of convective precipitation for the composite of each radar development level. . . . 104

7.3 Composite lifecycle characteristics for each MCS satellite classification. . 106

7.4 Composite lifecycle characteristics for each level of radar development. . 106 


\section{Chapter 1}

\section{Introduction}

Mesoscale convective systems (MCSs) provide a significant portion of the precipitation that falls over the central United States during the critical agricultural growing seasons of spring and summer. In fact, MCSs account for $30 \%$ to $70 \%$ of the warm-season precipitation in this area (Fritsch et al. 1986). Additionally, MCSs produce a broad range of severe convective weather events (Maddox et al. 1982 and Houze et al. 1990) that can be potentially damaging to crops and society in general. Given that MCSs have such a profound influence on the midlatitudes, it is important to study them and their development process.

Even though the importance of MCSs is well understood, there is much left to learn about the growth and development of these systems. One difficulty in understanding MCSs lies in the fact that often the mesoscale features important to MCS development are not well sampled by the operational large-scale observation network (Stensrud and Fritsch 1994). Thus, due to its global coverage, infrared satellite imagery has been an important means of studying MCSs, particularly mesoscale convective complexes (MCCs) (e.g. Maddox 1980, Maddox et al. 1982, and Maddox 1983). Although satellite images provide an effective way of identifying MCSs, they don't provide much information on the underlying convection. Consequently, 
radar data have been used to allow for more detailed studies of MCS convection (e.g. Bluestein and Jain 1985, Bluestein et al. 1987, Houze et al. 1990, and Parker and Johnson 2000).

Using these different sets of data, many studies have been carried out over the years on various types of MCSs covering different geographical areas. There are probably a couple of reasons for the variations in these studies. First of all, the development of technology and the radar network in the U.S. has permitted the study of more systems over a larger area. In addition, the availability and flexibility of digitized data and computing power have allowed studies to become increasingly extensive. Secondly, the assorted definitions of MCSs throughout the years have been relatively vague, as they should be, to include a variety of convective phenomena. For example, Zipser (1982) defined MCSs as, "cloud and precipitation systems, together with their associated circulation systems, which include a group of cumulonimbus clouds during most of the lifetime of the system." Definitions like this one allow for many interpretations, which has resulted in many types of MCS studies.

Certainly, a comprehensive study of MCSs would be helpful in supplementing the various MCS studies done previously. One purpose of this thesis is to provide a more comprehensive study of MCSs than many of the previous MCS studies in terms of number, MCS type, length of study, and geographical area considered. Another purpose of this thesis is to focus on the MCS growth stage to better characterize common patterns of development by which convection becomes organized into mature MCSs. In brief, the warm seasons (April-August) of 1996 through 1998 were examined to provide a large sample of MCSs. A significant portion of the central United States extending basically from the Rocky Mountains in the west to the Appalachian Mountains in the east and from the southern U.S. border to the northern 
U.S. border was chosen for this study. Choosing a larger spatial domain was done in hope to expand on previous single-radar studies (e.g. Bluestein and Jain 1985, Bluestein et al. 1987, and Houze et al. 1990). During the identification process, all systems subjectively deemed to be coherent based on infrared satellite imagery were recorded regardless of their size or shape. Again, this was an attempt to be more comprehensive in MCS type by expanding on MCC studies (e.g. Maddox 1980, Maddox 1983, and McAnelly and Cotton 1986), squall line or linear MCS studies (e.g. Bluestein and Jain 1985 and Parker and Johnson 2000), and even large system studies (e.g. Anderson and Arritt 1998). Selecting a wide assortment of MCS types over a large region of the U.S. inherently led to large MCS sample of 514 systems initially identified by infrared satellite imagery.

In addition to the MCSs being classified by their cold cloud top characteristics, their development as seen through radar imagery was categorized. Looking at the development of such a wide variety of systems should complement previous radar studies, such as Bluestein and Jain's (1985) study on the formation of Oklahoma squall lines. In addition, studying the development of different types of MCSs may lead to understanding the differences between the processes governing their development. Finally, representative soundings were examined as in previous MCS studies. The primary purpose for looking at the soundings was to provide some basic information on the environment in which these systems formed and to note obvious differences between systems based on either satellite classification or radar development classification.

The remainder of this thesis provides the details, description, and results of the analysis of this MCS sample. Chapter 2 provides information on relevant observational MCS studies done in the past. The third chapter provides a description of 
the data and methods used in this analysis. The infrared satellite classifications are defined and discussed in Chapter 4 along with some basic comparisons and examples. Chapter 5 discusses the method by which the MCSs were categorized according to their development. In addition, this chapter also provides some basic comparisons between each category and examples of each. The sixth chapter briefly discusses the similarities and differences among the environmental conditions of each MCS category as well as severe weather reports. A composite analysis of the MCS sample is discussed in Chapter 7. Finally, Chapter 8 provides a summary, conclusions, and suggestions for future research. 


\section{Chapter 2}

\section{Background}

Several MCS studies performed in the past have attempted to classify MCSs into discrete categories by a variety of different methods and perspectives. The most common methods of MCS classification involve analyzing satellite and radar characteristics of the systems. Similar to past studies, the present study attempts to classify MCSs to better understand the similarities and differences between the systems; however, unlike many past studies, this study will classify each MCS by both satellite and radar characteristics. Of course, nature doesn't necessarily make it; easy to sort out these systems into categories. In effect, there are numerous ways to analyze and classify MCSs that may be completely appropriate, but the multitude of methods may lead to confusion. The purpose of this chapter is to provide a background on MCS classification to help clarify the relationship among existing schemes, so it will be easy to relate them to the schemes used in this study (see Chapters $4 \& 5$ ).

It is necessary to first introduce the ubiquitous term, squall line. This term is probably the first instance of MCS "classification" even though it was used well before MCSs were defined. Bluestein and Jain (1985) provide a nice summary of the evolution of this term, noting that it is now loosely applied to both frontal and nonfrontal lines of thunderstorms. The fluctuating nature of the definition of squall 
line has led to ambiguity when using the term. Consequently, it has become common for authors to use "linear MCS," for example, instead of "squall line" in an attempt to avoid using the term. In any case, one must be careful when using the term to make sure there is no uncertainty about its meaning. From its inconspicuous beginning, the area of MCS classification has blossomed with the advent of satellites and radar. Several studies on both satellite and radar classifications have emerged in the past twenty years.

\subsection{Satellite classification of MCSs}

Maddox (1980) was the first to classify a particular type of MCS by means of satellite imagery. He noticed a high frequency of organized, meso- $\alpha$ (see Orlanski 1975) convective weather systems moving across the central U.S. He termed these massive systems "mesoscale convective complexes" (MCCs). He based the definition of MCCs on typical infrared satellite characteristics possessed by systems moving across the central United States (see Table 2.1).

The physical characteristics described in Table 2.1 are somewhat arbitrary, but were chosen to ensure that only large, well-organized, and active systems were classified as MCCs. Although Maddox (1980) focused primarily on MCCs, he does suggest a classification scheme for MCSs based on location (tropics or midlatitudes), shape (linear or circular), and size (meso- $\alpha$ or meso- $\beta$ ). As will be discussed in Chapter 4 , the present study uses a very similar infrared satellite classification scheme for the midlatitudes.

The nomenclature "MCC" has been widely used, and its definition has not been abused as is the case with "squall line." There has been one relatively minor 
Table 2.1: Definition of mesoscale convective complex (MCC) (Maddox 1980). (based upon analysis of infrared satellite imagery)

\begin{tabular}{|c|c|}
\hline \multicolumn{2}{|r|}{ Physical characteristics } \\
\hline Size: & $\begin{array}{l}\text { A Cloud shield with continuously low IR temperature } \\
\text { temperature } \leq-32^{\circ} \mathrm{C} \text { must have an area } \geq 100,000 \mathrm{~km}^{2} \\
\text { B-Interior cold cloud region with temperature } \\
\leq-52^{\circ} \mathrm{C} \text { must have an area } \geq 50,000 \mathrm{~km}^{2}\end{array}$ \\
\hline Initiate: & Size definitions $A$ and $B$ are first satisfied \\
\hline Duration: & $\begin{array}{l}\text { Size definitions } A \text { and } B \text { must be met for a period } \\
\geq 6 \mathrm{~h}\end{array}$ \\
\hline $\begin{array}{l}\text { Maximum } \\
\text { extent: }\end{array}$ & $\begin{array}{l}\text { Contiguous cold cloud shield (IR temperature } \\
\leq-32^{\circ} \mathrm{C} \text { ) reaches a maximum size }\end{array}$ \\
\hline Shape: & $\begin{array}{l}\text { Eccentricity (minor axis/major axis) } \geq 0.7 \text { at time } \\
\text { of maximum extent }\end{array}$ \\
\hline Terminate: & Size definitions A and B no longer satisfied \\
\hline
\end{tabular}

modification to the definition of MCCs. Augustine and Howard (1988) removed the $\leq-32^{\circ} \mathrm{C}$ size requirement of the cloud shield. They dismissed this criterion for several reasons. First of all, it allows the process to be more automated as often it is much easier to delineate between systems using the $-52^{\circ} \mathrm{C}$ threshold as opposed to the $-32^{\circ} \mathrm{C}$ threshold. Secondly, they added that McAnelly and Cotton (1985) found a majority of precipitation from an $\mathrm{MCC}$ falls out of the $-52^{\circ} \mathrm{C}$ region. Finally, they showed that for most MCCs there is a linear relationship between the area of the $-32^{\circ} \mathrm{C}$ threshold and the area of the $-52^{\circ} \mathrm{C}$ threshold. Table 2.2 shows the modified MCC definition. This is probably the more widely used MCC definition today and will be used for this study.

Although MCCs are massive, striking systems, they represent only a small fraction of the total MCSs that exist in nature. Anderson and Arritt (1998) performed a study on MCCs and another large class of MCSs, persistent elongated convective systems (PECS). PECS are what you might call the "linear" version of MCCs. The only difference between a MCC and a PECS is the shape of the system. PECSs 
Table 2.2: Modified MCC definition (Augustine and Howard 1988).

\begin{tabular}{|c|c|}
\hline \multicolumn{2}{|r|}{ Physical characteristics } \\
\hline Size: & $\begin{array}{l}\text { Cloud shield with continuously low IR temperature } \\
\text { temperature } \leq-52^{\circ} \mathrm{C} \text { must have an area } \geq 50,000 \mathrm{~km}^{2}\end{array}$ \\
\hline Initiate: & Size definition is first satisfied \\
\hline Duration: & Size definition must be met for a period $\geq 6 \mathrm{~h}$ \\
\hline $\begin{array}{l}\text { Maximum } \\
\text { extent: }\end{array}$ & $\begin{array}{l}\text { Contiguous cold cloud shield (IR temperature } \\
\leq-52^{\circ} \mathrm{C} \text { ) reaches a maximum size }\end{array}$ \\
\hline Shape: & $\begin{array}{l}\text { Eccentricity (minor axis/major axis) } \geq 0.7 \text { at time } \\
\text { of maximum extent }\end{array}$ \\
\hline Terminate: & Size definition no longer satisfied \\
\hline
\end{tabular}

have eccentricities between 0.2 and 0.7 while MCCs must have eccentricities $\geq 0.7$ (see Table 2.2). All of the other criteria (i.e. size and duration) are the same for both MCCs and PECSs. In their study, Anderson and Arritt (1998) found that PECSs occurred about twice as frequently as MCCs, which is not astonishing since the definition of PECS involves the removal of the arbitrary eccentricity stipulation. Due to their potential to produce significant and severe weather, PECSs cannot be ignored just because they do not meet certain shape characteristics of a particular definition. However, there are still many smaller MCSs (e.g. Knupp and Cotton 1987) that have not been addressed by satellite classification. One feature of the present study is to include these smaller systems with the larger systems (MCCs and PECSs) in a MCS study.

\subsection{Radar classification of MCSs}

In addition to classifying MCSs according to infrared satellite characteristics, there have also been many attempts to classify MCSs by their radar characteristics. However, unlike the satellite classification process where there is a "standard" method of categorizing systems, the radar classification process has been less standardized. 
One common method of classifying MCSs by radar has been to lock at the arrangement of the convective and stratiform regions of a mature MCS (e.g. Houze et al. 1990 and Parker and Johnson 2000). Another common, yet different, method of MCS radar classification has been to classify MCSs based on their developmental or formational stages (e.g. Bluestein and Jain 1985, Bluestein et al. 1987, and Lochrer and Johnson 1995). It is worth noting that most of these studies have focused on squall lines or linear MCSs. The present study attempts to classify all systems (both linear and circular) focusing on the stages of development (see Chapter 5).

\subsubsection{Radar classification by organization}

Categorizing MCSs according to their organization deals with the location of the convective line of the storm in relation to the stratiform region of the storm. Houze et al. (1990) performed a single-radar study in Oklahoma looking at "mesoscale precipitation systems" that passed through the area. They categorized the systems based on the degree to which they were of "leading-line trailing-stratiform" (TS) structure and whether or not the systems were deemed to be "symmetric" or "asymmetric" (see Fig. 2.1). They discovered that 42 systems, or two-thirds of the systems in their study, could be considered either weakly, moderately, or strongly classifiable as a TS precipitation system. The remaining systems (21) were regarded to be unclassifiable. Of the classifiable systems, there was approximately an equal number of symmetric, asymmetric, and intermediate systems.

Houze et al. (1990) also looked at previously documented MCCs and their relationship to the systems they were studying. Whenever a MCC passed through the region of interest, a major rain event meeting their criteria occurred. However, $75 \%$ of their systems did not occur in conjunction with a cloud shield that met 


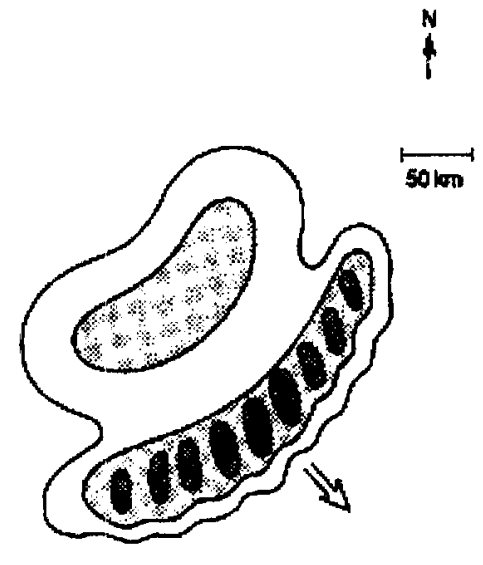

SYMMETALC CASE

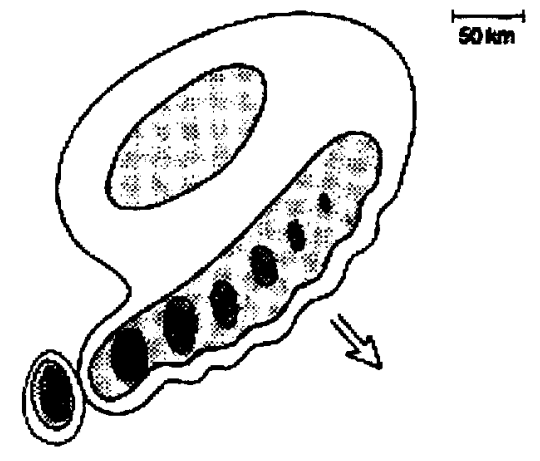

ASYMMETRIC CASE

Figure 2.1: Schematic of symmetric (left) and asymmetric (right) leading-line trailingstratiform MCSs (from Houze et al. 1990).

MCC criteria. This certainly suggests that other MCSs not meeting the strict MCC definition might be important precipitation-producing systems.

In related work, Schiesser et al. (1995) analyzed the structure of "severe precipitation systems" in Switzerland. In addition to the trailing stratiform (TS) systems described by Houze et al. (1990), Schiesser et al. (1995) also documented leading stratiform systems (LS) and systems without a stratiform precipitation region (referred to as none)(see Fig. 2.2).

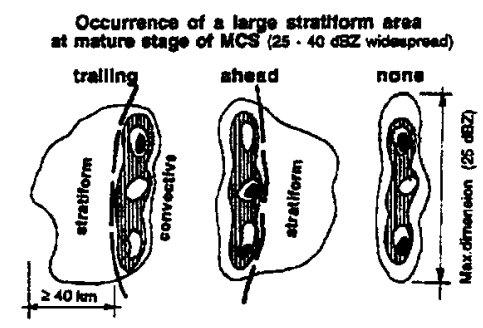

Figure 2.2: Schematic reflectivity drawings of Swiss mesoscale convective systems (from Schiesser et al. 1995).

This work led to a similar study of MCS organization in the central United 
States by Parker and Johnson (2000). In addition to the TS and LS archetypes, they added a third mode of MCS arrangement: parallel stratiform (PS) systems (see Fig. 2.3). In fact, Parker (1999) believes that many of the systems classified with no stratiform precipitation in the Schiesser et al. (1995) study may actually correspond to the PS archetype. Parker and Johnson (2000) noted that linear MCSs frequently evolve among the archetypes during their lifecycle; therefore, the systems were classified based upon their predominant organizational mode. They found that the TS archetype was the dominant form of MCS organization in the central U.S. However, both the LS and PS archetypes each accounted for about $20 \%$ of the studied population of MCSs. Thus, these systems are very common in the U.S. and necessitate future study.

\section{Linear MCS archetypes}

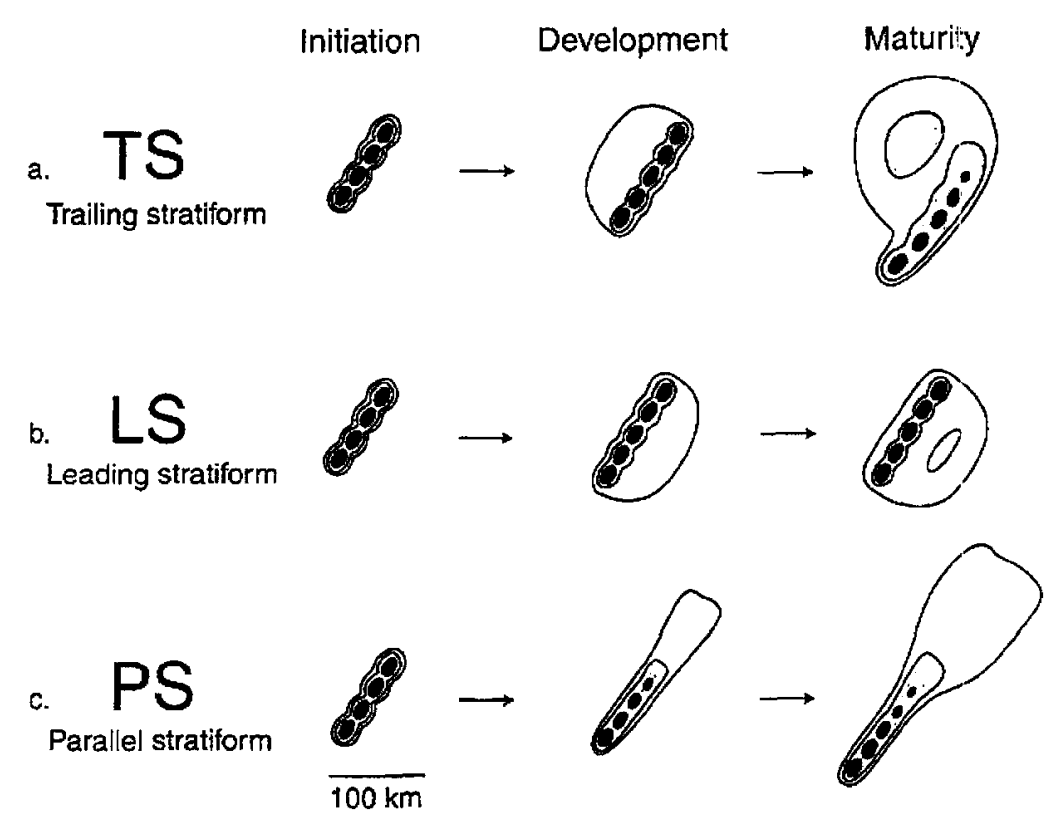

Figure 2.3: Schematic reflectivity drawing of idealized lifecycles for three linear MCS archetypes: (a) TS, (b) LS, and (c) PS (from Parker and Johnson 2000).

Although the primary focus of the present study is not on the radar classification 
of MCSs by their organization, each system was casually examined and categorized by their predominant arrangement using the archetypes discussed in Parker and Johnson (2000) (see Chapter 5). It is important to stress that the studies mentioned in this section primarily focused on convective lines, leaving the topic of non-linear convective systems relatively untouched.

\subsubsection{Radar classification by development}

The concept of classifying MCSs by their development is of greater importance to the focus of the present study. Classifying systems by their organization involves looking at the precipitation structure of mature MCSs while classifying systems by their development involves tracing back from the mature stages of MCSs to the formative stages to see the arrangement of convection at initiation. The intent of studying the development of MCSs lies in the desire to understand the different types of convective arrangements that ultimately lead to mature MCSs.

Bluestein and Jain (1985) performed the first study of this type seeking to identify common patterns of severe squall line formation. They considered the general definition of squall line (i.e. "a linearly oriented mesoscale convective system"). In their examination of the radar data for Norman, Oklahoma, they broke squall line development into four classifications: broken line, back building, broken areal, and embedded areal (see Fig. 2.4). Out of the 52 squall lines they studied, 14 formed by broken line, 13 formed by back building, 8 formed by broken areal, and 6 formed by embedded areal arrangements. The remaining 10 systems did not fit into a classification. Bluestein and Jain (1985) also observed satellite images to determine if the formation of squall lines could be discerned independently of radar. They found that the broken line and back building types of formation were the easiest to distinguish 
using satellite imagery. However, they made no attempt beyond this to observe and classify squall lines by satellite characteristics. In a closely related study, Bluestein et al. (1987) studied the formation of non-severe squall lines in Oklahoma. One of the differences is that many more non-severe squall lines formed through the broken areal process and fewer formed by back building as compared to severe squall line formation.

CLASSIFICATION OF SOUALL-LINE

DEVELOPMENT

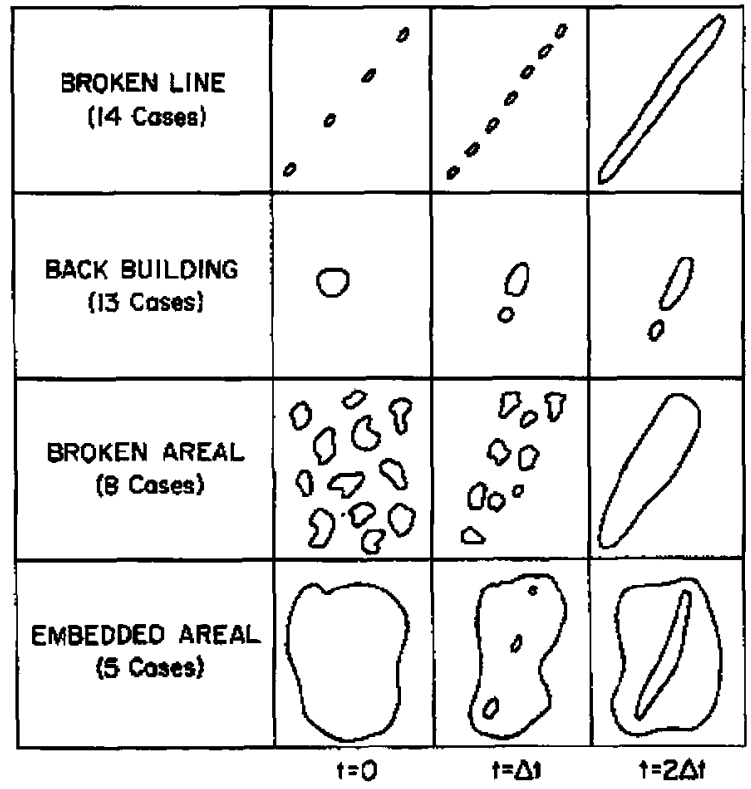

Figure 2.4: Idealized depictions of squall line formation (from Bluestein and Jain 1985).

Another study on the classification of MCS development was done by Blanchard (1990). This study is descended from Bluestein and Jain (1985), but it is unique in its own right. In relation to the present study, the most important feature of the study done by Blanchard (1990) is the inclusion of all types of MCSs in the classification scheme. Unfortunately, however, none of the terminology used by Bluestein and Jain (1985) is repeated. Blanchard (1990) identified three mesoscale convective patterns for 
the Oklahoma-Kansas Preliminary Regional Experiment for STORM-central (PRESTORM) field program: linear convective systems, occluding convective systems, and chaotic convective systems (see Fig. 2.5). From the 25 systems studied, 17 were classified as linear convective systems, 2 were classified as occluding systems, and 6 were classified as chaotic systems. This classification scheme is probably not as widely used as other schemes due to vagueness of the categories and terminology (see Doswell 1991 and Parker 1999). More than likely, viewing the cloud shields of these systems with satellite imagery would have cleared up some of the confusion, especially for the chaotic convective systems. Regardless, it was a worthy attempt of classifying all types of MCSs.

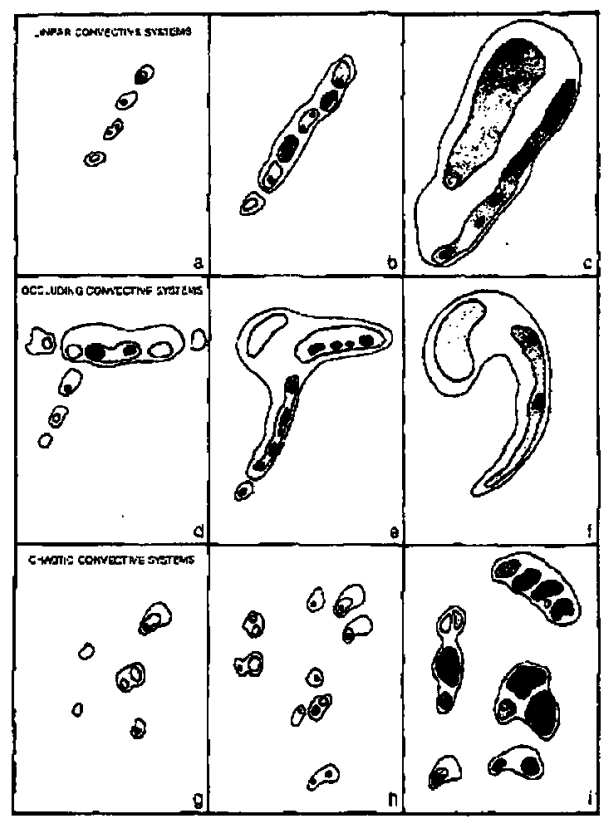

Figure 2.5: Schematic reflectivity evolution of three convective modes during the PRE-STORM program: (a-c) linear convective systems, (d-f) occluding convective systems, and (g-i) chaotic convective systems. (from Blanchard 1990).

A more recent and specific study by Loehrer and Johnson (1995) looked at different development paths of MCSs to reach an asymmetric TS structure. Disorganized, linear, back-building, and intersecting convective bands were the four types 
of development they identified (see Fig. 2.6). The numbers in Figure 2.6 represent the number of systems observed for each classification in the 1985 PRE-STORM field program. Out of the few cases they studied, a dominant evolutionary mode did not emerge. One important aspect of their classification is the idea of interaction between convective bands, which will be implemented into the classification scheme in the present study (see Chapter 5).

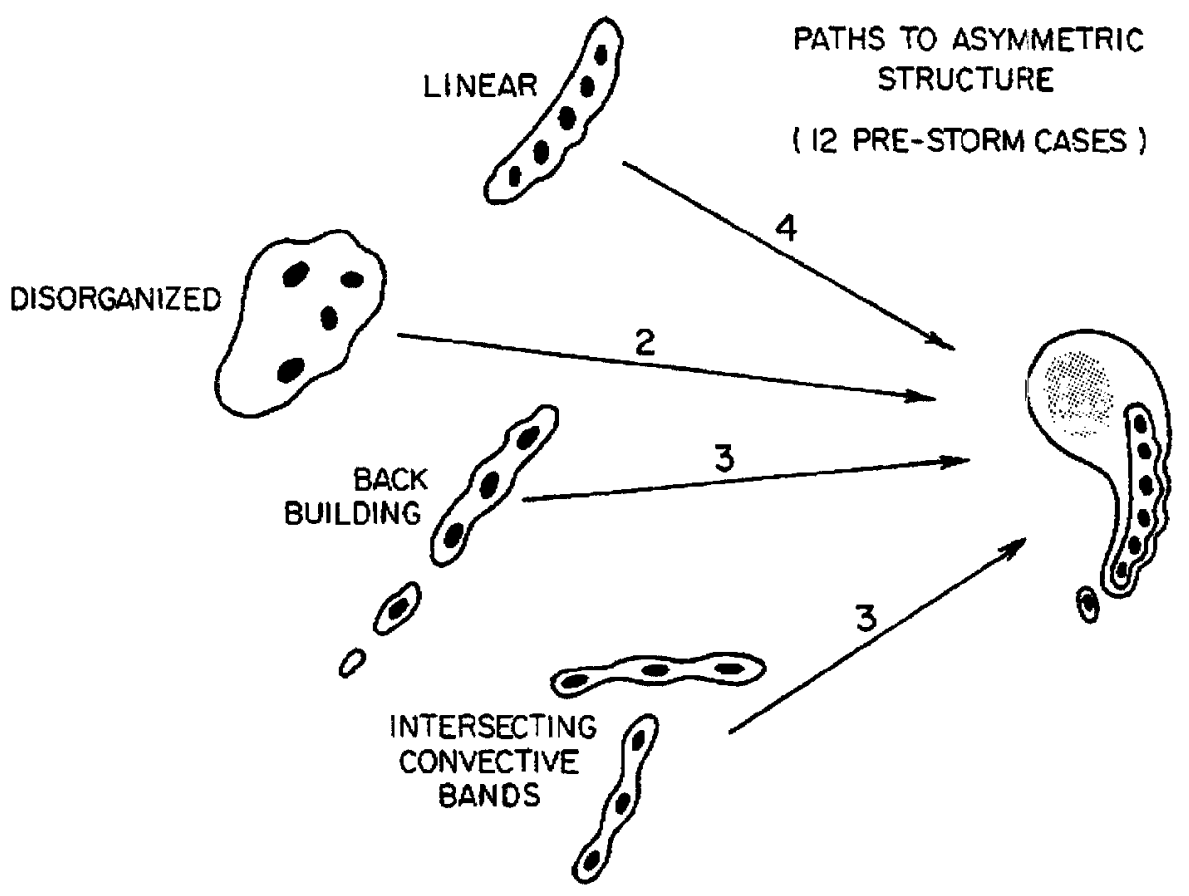

Figure 2.6: Schematic of the paths to reach asymmetric structure observed by Loehrer and Johnson (1995) (from Hilgendorf and Johnson 1998).

In summary, there have been many worthwhile studies on classifying MCSs by either satellite or radar characteristics. The satellite classification schemes have been well-defined by cloud shield characteristics of the system. The radar classification schemes have been much less well-defined due to the complex nature of convection as depicted by radar echoes. In addition, there have been multiple viewpoints on the radar classification of MCSs, which is certainly valid. The present study is another 
attempt to create MCS classification schemes that might provide a contribution in understanding these systems by building upon past studies. 


\section{Chapter 3}

\section{Data and methods of analysis}

From this point on, the focus of this thesis shifts from past studies to the present study. This chapter provides basic information about the time period and area of interest for this study. In addition, details are supplied about the different types of data utilized and the way in which they were analyzed. All told, the chapter reviews the approach used to study the sample of MCSs.

\subsection{Study area and period}

In reality, the time frame and area studied are relatively arbitrary variables that are selected to meet the author's interests and goals. For this study, one goal was to study a large sample of MCSs. Thus, it would make sense to select a reasonably long time period and large domain to reach that goal. In the spirit of Maddox (1980), it was decided to study the majority of the active convective season of the central United States. Based on the number of MCCs he observed per month, the range of April through August seemed appropriate. In addition, the months of April, May, and June analyzed in springtime studies, such as Houze et al. (1990) and Bluestein and Jain (1985), are obviously included in this time frame. Furthermore, a three 
year period was selected to try to get a large and varied sample of MCSs and to remove any annual bias. It was desirable to study most of the United States, so only areas west of the Rocky Mountains and east of the Appalachian Mountains were not considered. Additionally, the initiation and development of MCSs is less frequent in these areas as opposed to the central United States. Thus, any MCS that had its convective initiation between $24^{\circ}-51^{\circ} \mathrm{N}$ and $82^{\circ}-115^{\circ} \mathrm{W}$ was considered for this study (see Fig. 3.1). The area and period studied proved to be sufficient in achieving a large sample of MCSs as several hundred systems were initially identified during the fifteen months included in the investigation.

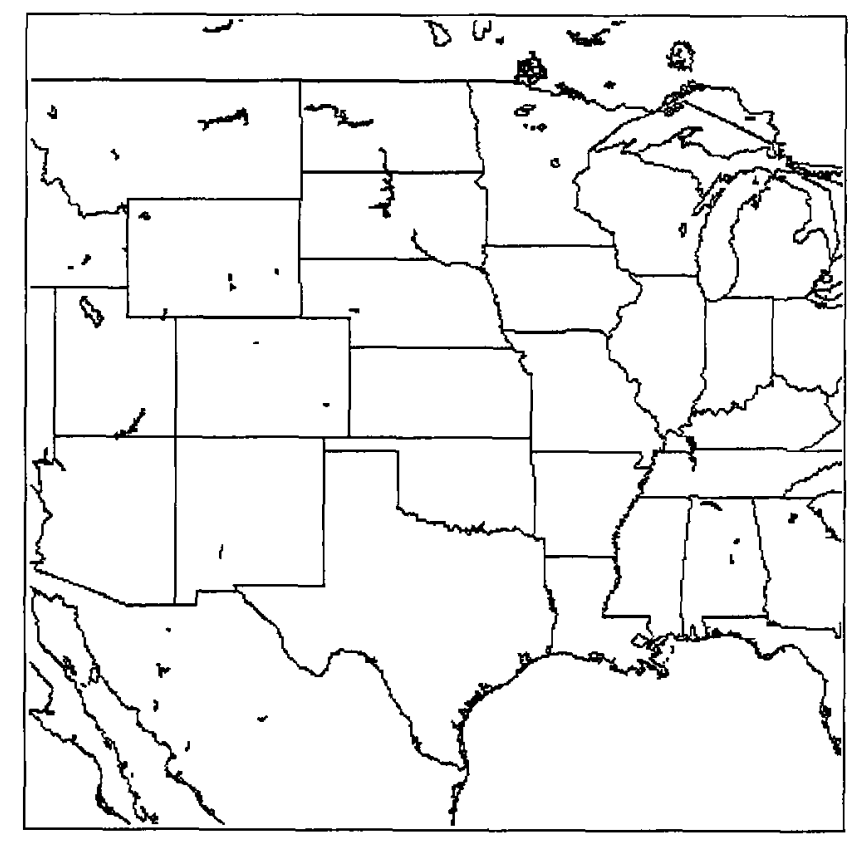

Figure 3.1: Geographical area considered in the study. 


\subsection{Satellite data}

The first step in this study was to identify the sample of MCSs using satellite imagery. It is generally easier to identify MCSs by their cold clovd shield than by their radar reflectivity patterns, as the underlying convection can take many forms (see Blanchard (1990)). The cold cloud shield is larger than the area of convection and often is more contiguous making it easier to identify and study a large number of systems. The rest of this section discusses the satellite dataset and the methods used in analyzing the data to obtain information on the lifecycle of the MCSs.

\subsubsection{Dataset information}

The satellite data for the three-year period (1996-1998) were obtained from the Global Hydrology Resource Center (GHRC) at the Global Hydrology and Climate Center in Huntsville, Alabama. The dataset is comprised of hourly global composite infrared images from four weather satellites in geosynchronus orbit: GMS, GOES-8, GOES-9, and Meteostat. The Storm Prediction Center (SPC) creates the composite image, and the GHRC ingests it real-time. The resolution of the data is $14 \mathrm{~km}$ in the horizontal, which is sufficient for identifying MCSs, but does not provide detailed cloud structure information. Occasionally, there were missing data (most notably July 1-7, 1996), but overall it was a consistent dataset that provided fundamental information about each MCS.

\subsubsection{Satellite analysis}

Naturally, in order to study MCSs, a sample of MCSs needs to be identified. The infrared satellite data were converted from brightness counts into blackbody 
temperature, and the hourly files of the region of interest were plotted at three temperature contours $\left(-52^{\circ},-32^{\circ}\right.$, and $\left.-10^{\circ} \mathrm{C}\right)$ following Maddox's (1980) MCC study. Two 12-panel plots were created, printed, and reviewed for each day during the 15month period. As discussed in Section 2.1 , the $-52^{\circ} \mathrm{C}$ temperature threshold was the primary contour considered when reviewing the satellite images. This initial MCS identification process was very subjective. Any system developing in the region of interest that appeared to have contiguous, coherent structure at the $-52^{\circ} \mathrm{C}$ temperature threshold for a few hours was recorded as a MCS. The size and shape of the systems were really not a serious consideration at this point because those issues would be dealt with at a later point. It was important to be lenient in this first stage of identification because a large sample of all types of MCSs was desired, and later steps in the classification process were sure to eliminate some systems. Indeed, a total of 643 systems were identified for the three warm seasons after the first step with more steps to come.

The next step was to gather size, centroid, and eccentricity information for each hour during the MCS lifecycle in order to be able to classify the systems. A modified version of a program written by Augustine (1985) was used to document the systems. One modification made to the program allows the user to isolate specific cloud shields by drawing a polygon around them, so that only the system of interest is considered. Thus, each hourly satellite image of the MCS was analyzed with this program to produce information on its lifecycle. With this information, plots of the MCS tracks and area could be produced for each system (e.g. Fig. 3.2). During this stage, several more systems were discarded due to lack of cohesiveness, missing data, or border issues. Consequently, a total of 514 systems were left for the satellite classification process. 

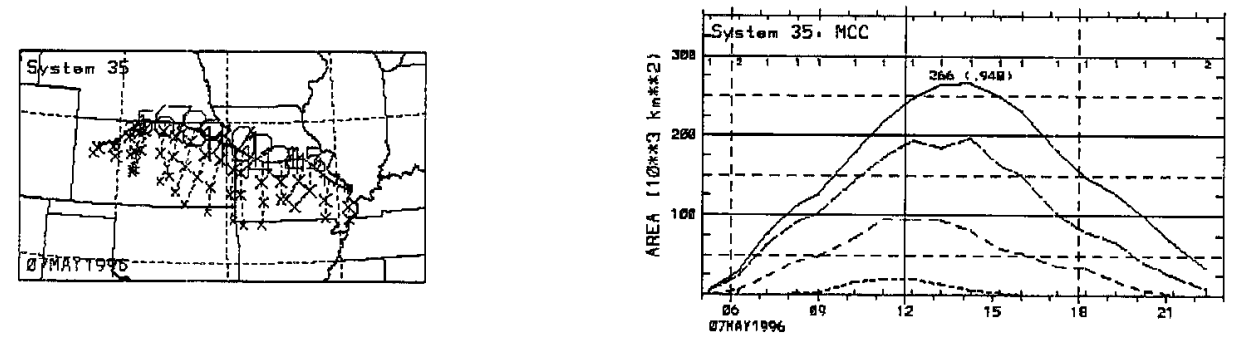

Figure 3.2: Example plot of a MCC track across Kansas and Missouri on May 7, 1996 (left) and its corresponding area over time at the $-52^{\circ},-58^{\circ},-64^{\circ}$ and $-70^{\circ} \mathrm{C}$ cloud top temperature thresholds (right).

The remaining systems were classified according to their size, shape, and duration. The categories were devised to be consistent with previous satellite classification studies, so that the results would follow and allow comparison to preceding studies. Ultimately, 465 systems fit into one of four satellite categories. The satellite classification process will be discussed in much greater detail in Chapter 4.

\subsection{Radar data}

Another important aspect of this study was to address the issue of MCS development. While satellite imagery is useful for getting a broad viewpoint of MCSs, it is not helpful in studying the small-scale structure of MCS development. Therefore, radar reflectivity data were used to examine the systems at a higher temporal and spatial resolution. Since the MCSs had already been identified by means of infrared satellite, the radar data could be used to study the development and arrangement of the underlying convection of these predetermined systems. The remainder of this section will address information on the radar dataset and how the data were analyzed. 


\subsubsection{Dataset information}

The radar data were also obtained from the GHRC. The radar images are national reflectivity composites, which are very convenient images for examining a significant portion of the United States, as in this study. Weather Services International (WSI) generates these composite products (i.e. WSI NOWrad (TM) products) with data from the National Weather Service (NWS) radars in the continental United States. They quality control the images in real-time before the GHRC receives them. The data are arranged into sixteen bins of $5 \mathrm{dBZ}$ intervals with a resolution of $2 \mathrm{~km}$ x $2 \mathrm{~km}$ and are available at 15-minute intervals. The spatial and temporal resolution is not adequate to follow an individual convective cell throughout its lifecycle; however, the resolution is sufficient for studying the overall organization and evolution of large convective cells and meso- $\beta$ scale convective clusters. Since the dataset was very consistent with very little missing data, it proved to be a useful tool for viewing the development of MCSs over the central United States.

\subsubsection{Radar analysis}

With the MCSs already identified by means of satellite imagery, the first stage of radar analysis was to correlate the radar echoes with the cloud shields of the MCSs. As was done with the satellite images, the radar images were plotted at three thresholds to recognize the systems: 20,30 , and $40 \mathrm{dBZ}$. Once again, two 12-panel plots of hourly radar images were created, printed, and reviewed for each day of the period to identify the MCSs by their radar characteristics. It became obvious after reviewing the radar images that the radar coverage was not sufficient to capture many of the systems, especially into Canada to the north and into Mexico and the 
Gulf of Mexico to the south. This was certainly expected as the geographical region considered extends beyond the radar coverage of the continental United States (see Fig. 3.1). For the most part, a significant convective structure on radar imagery could easily be associated with its cloud shield on satellite imagery.

The next step of radar processing was also very similar to that of satellite processing. Another modified version of Augustine's (1985) program was developed to work with the radar data to obtain size, centroid, eccentricity, and reflectivity characteristics for the radar lifecycle of each MCS. This exhaustive process of analyzing each 15-minute image during the lifecycle of every MCS produced a wealth of information about the systems. With this information, plots of the 15 largest convective clusters at a given $\mathrm{dBZ}$ threshold were plotted along with the rainfall characteristics of the system (e.g. Fig. 3.3). The Z-R relationship used to calculate the rain rate in this study was proposed by Woodley et al. (1975):

$$
Z=300 R^{1.4}
$$

This relationship is used by the GHRC when producing composite daily rainfall maps and is also the default algorithm used for the NEXRAD radars (Fulton et al. 1998). Even though the radar images are quality-controlled, it is worth mentioning that there still may be instances of radar attenuation, bright band effects, and anomalous propagation that may alter the actual reflectivity fields. Nevertheless, an attempt was made to minimize these effects by only looking at the averages of a large number of systems. As previously mentioned, many of the remaining systems did not develop and stay within the range of the radar network. Consequently, there was a total of 387 MCSs with a complete set of both satellite and radar data, which is a sufficient number to consider having a "large" sample. 

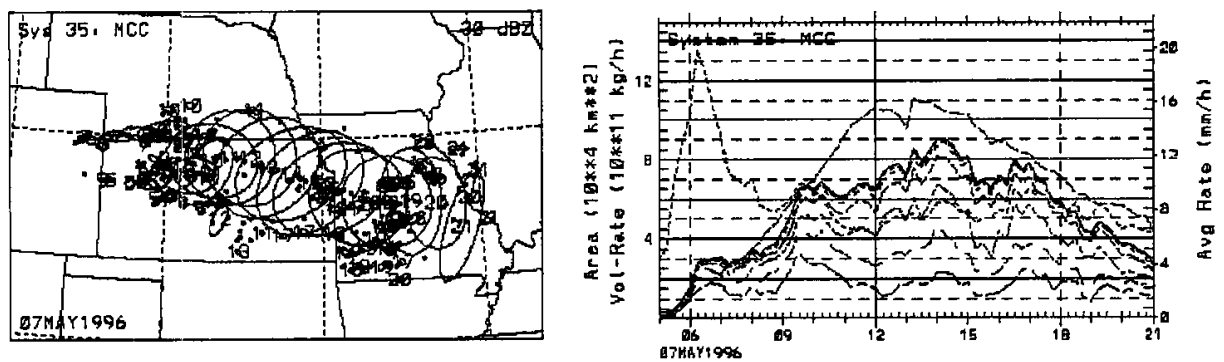

Figure 3.3: Example plot of the same system as Fig. 3.2 with convective cluster (30 $\mathrm{dBZ}$ threshold) development over time (left) and the average rain rate (small dashed line), precipitating (i.e. $\geq 20 \mathrm{dBZ}$ ) area (thick dashed line), and volumetric rain rate (solid line) with contributions from $\mathrm{dBZ}$ thresholds at $5 \mathrm{dBZ}$ increments below that (long dashed lines) (right).

Once again, the last step involved classifying the systems. Unlike the satellite classification process, however, the radar classification process was much more subjective. The focus of the radar classification was on the developmental stages of the MCSs, so it was the intent to incorporate as much as possible from similar previous studies (see Section 2.2.2) into the classification scheme. The best way to view the systems and classify them was to animate the 15-minute images and analyze the system's development many times. This process and the resulting classification scheme will be discussed in much more detail in Chapter 5 .

\subsection{Sounding data and severe weather reports}

Sounding data were the last type of data used in analyzing the MCS sample. It is noteworthy that examining the soundings of these systems was not an initial goal of the study, but it was performed to provide some information on the environment in which the MCSs formed. The NWS sounding data were obtained from an online archive maintained by the University of Wyoming Department of Atmospheric Science. Similar to previous MCS studies (e.g. Rasmussen and Wilhelmson 1983, 
Houze et al. 1990, and Parker and Johnson 2000), an individual sounding was chosen to be the most representative sounding of the airmass in which the MCS formed and was used without modification. Further efforts to interpolate nearby soundings (see Bluestein and Parks 1983 and Bluestein and Jain 1985) or to modify operational soundings with numerical models (see Brooks et al. 1994) were not undertaken due to the large volume of MCSs studied and the fact that it wasn't the primary focus of the study. The data were processed in order to construct average soundings. In doing this, the mandatory and significant-level information were interpolated to get levels at $25 \mathrm{mb}$ intervals from the surface to $100 \mathrm{mb}$. The soundings were then grouped according to their radar and satellite classifications and analyzed by looking at both the average properties of the soundings and the properties of the average soundings. In addition, severe weather reports for this time period were obtained from the Storm Prediction Center and recorded for each MCS. A detailed discussion of the results is provided in Chapter 6. 


\section{Chapter 4}

\section{Satellite classification of MCSs}

Classification of MCSs by satellite characteristics has certainly been done in the past (see Section 2.1); however, there has been little recognition of all types of MCSs when viewing satellite imagery. In order to produce a useful and commendable taxonomy, it is important to build upon and be consistent with previous studies. The satellite classification scheme presented in this chapter is an attempt to do just that. In addition, it was developed to be more inclusive of MCSs, especially smaller systems. The rest of the chapter provides a description of the classification scheme, presents some basic characteristics of each category, and offers some examples.

\subsection{Definition of classes}

The cornerstone of MCS classification by satellite imagery is the definition of MCCs by Maddox (1980). Thus, the method he used to define MCCs was the basis of the classification scheme presented in this chapter. It is noteworthy to mention an alternative definition for MCCs set forth by Cotton et al. (1989) that defines a MCC as a "nearly geostrophically-balanced MCS with a horizontal scale comparable to or larger than the Rossby radius of deformation, $\lambda_{R}$." For this study, however, it was 
more convenient and practical to use Maddox's (1980) MCC definition as the basis for defining the other types of MCSs. Essentially, the systems were classified according to their size, duration, and eccentricity of the $-52^{\circ} \mathrm{C}$ cloud-top temperature threshold (see Table 2.2). As discussed in Section 2.1, the large systems, MCCs and PECSs, have been well defined and documented. Consequently, these two types of systems comprise two of the four categories. The relatively undocumented systems are the smaller MCSs; therefore, categories should be defined to include these systems.

Since the large MCSs are discriminated by shape (i.e. MCC for circular systems and PECS for linear systems), it is natural to create two categories for smaller MCSs: one for circular systems and one for linear systems. Consequently, the eccentricity criterion will be the same for the smaller systems as for the larger systems. The only criteria that are left to be set for the smaller systems are the size and duration of the cloud shield at the $-52^{\circ} \mathrm{C}$ threshold. These minimum criteria are important because they basically set the definition of a MCS for this study. As discussed in Parker and Johnson (2000), the appropriate MCS time scale is $f^{-1}$, which is approximately 3 hours for the midlatitudes. Thus, the duration criterion for the smaller MCSs was set at $\geq 3 \mathrm{~h}$.

The size criterion was somewhat more difficult and arbitrary to assign for the smaller systems than the time scale. Some studies have suggested an MCS length scale of $100 \mathrm{~km}$ (e.g. Houze 1993 and Parker and Johnson 2000). This seems appropriate, but they were considering the scale of convective radar echoes, and cloud shields grow much larger than the area of the underlying convection. Hence, a somewhat larger scale was desired. The reexamination of several of the small systems led to the conclusion that the most coherent systems reached an area of at least $30,000 \mathrm{~km}^{2}$. 
Thus, the size criterion for the smaller systems was set at $\geq 30,000 \mathrm{~km}^{2}$ with the caveat that their maximum size must be at least $50,000 \mathrm{~km}^{2}$ as a way of connecting the definition of the smaller systems to the larger systems. To keep the naming convention as simple as possible, the smaller circular systems are referred to as meso- $\beta$ MCCs (MBMCCs) and the smaller linear systems are called meso- $\beta$ PECSs (MBPECSs). From Orlanski's (1975) definitions of meteorological scales, the larger MCSs fit more appropriately into the meso- $\alpha$ scale while the smaller MCSs fit more appropriately into the meso- $\beta$ scale, hence the reasoning for the nomenclature. Table 4.1 shows the definitions of the four classes of MCSs according to infrared satellite characteristics: $M C C, P E C S, M \beta M C C$, and $M \beta P E C S$.

Table 4.1: MCS definitions based upon analysis of infrared satellite data

\begin{tabular}{|c|c|c|c|}
\hline MCS Category & Size & Duration & Shape \\
\hline $\mathrm{MCC}$ & $\begin{array}{l}\text { Cold cloud region } \\
\leq-52^{\circ} \mathrm{C} \text { with area } \\
\geq 50,000 \mathrm{~km}^{2}\end{array}$ & $\begin{array}{l}\text { Size definition met } \\
\quad \text { for } \geq 6 \mathrm{~h}\end{array}$ & $\begin{array}{c}\text { Eccentricity } \geq 0.7 \\
\text { at time of maximum } \\
\text { extent }\end{array}$ \\
\hline PECS & $\begin{array}{l}\text { Cold cloud region } \\
\leq-52^{\circ} \mathrm{C} \text { with area } \\
\geq 50,000 \mathrm{~km}^{2}\end{array}$ & $\begin{array}{l}\text { Size definition met } \\
\text { for } \geq 6 \mathrm{~h}\end{array}$ & $\begin{array}{c}0.2 \leq \text { Eccentricity }<0.7 \\
\text { at time of maximum } \\
\text { extent }\end{array}$ \\
\hline $\mathrm{M} \beta \mathrm{MCC}$ & $\begin{array}{l}\text { Cold cloud region } \\
\leq-52^{\circ} \mathrm{C} \text { with area } \\
\geq 30,000 \mathrm{~km}^{2} \& \\
\text { maximum size must } \\
\text { be } \geq 50,000 \mathrm{~km}^{2}\end{array}$ & $\begin{array}{l}\text { Size definition met } \\
\quad \text { for } \geq 3 \text { hours }\end{array}$ & $\begin{array}{c}\text { Eccentricity } \geq 0.7 \\
\text { at time of maximum } \\
\text { extent }\end{array}$ \\
\hline M $\beta$ PECS & $\begin{array}{l}\text { Cold cloud region } \\
\leq-52^{\circ} \mathrm{C} \text { with area } \\
\geq 30,000 \mathrm{~km}^{2} \& \\
\text { maximum size must } \\
\text { be } \geq 50,000 \mathrm{~km}^{2}\end{array}$ & $\begin{array}{l}\text { Size definition met } \\
\quad \text { for } \geq 3 \text { hours }\end{array}$ & $\begin{array}{c}0.2 \leq \text { Eccentricity }<0.7 \\
\text { at time of maximum } \\
\text { extent }\end{array}$ \\
\hline
\end{tabular}

Reviewing Table 4.1 shows that many shapes and sizes of MCSs are included in the classification scheme. The MCC definition is the modified version of Maddox's (1980) definition (see Table 2.2) as set forth by Augustine and Howard (1988) 
while the PECS definition is that as defined by Anderson and Arritt (1998). As was discussed above, M $\beta$ MCCs and M $\beta$ PECSs are just smaller, abbreviated versions of their namesakes. Including such a broad range of systems led to a large MCS sample, which was desired for this study. The classification scheme presented here will be used throughout the rest of the paper.

\subsection{Basic characteristics}

As discussed in Section 3.2.2, a total of 514 systems were identified and subjected to the classification scheme. During the classification process, it was expected to eliminate some systems due to the way in which the systems were subjectively identified. In fact, a total of 49 systems were removed from consideration through the classification process. Two systems were removed because their eccentricity was $<0.2$, twenty-two systems were removed because they failed to reach a maximum size of $50,000 \mathrm{~km}^{2}$ even though they met the duration requirement at the size of 30,000 $\mathrm{km}^{2}$, and twenty-five systems were removed because they did not meet the duration criteria of $\geq 3$ hours at a size of $30,000 \mathrm{~km}^{2}$. Consequently, a total of 465 classifiable systems remained.

Table 4.2 provides a breakdown of MCS frequency for each of the five months during the three-year period. Looking at the totals, more systems fit into the larger MCS classifications (MCCs and PECSs) than the smaller MCS classifications (M $\beta$ MCCs and M $\beta$ PECSs). MCCs and PECSs accounted for $64 \%$ of the MCSs during the study period. PECSs were by far the most common type of MCS accounting for $40 \%$ of the sample total. As far as the monthly totals are concerned, May, June, and July were about equally the most common months for MCS occurrence. April was by far the 
least likely month for an MCS to develop accounting for less than $10 \%$ of the total sample. Another interesting observation is that the greatest frequency of smaller systems tended to occur later in the season as opposed to the larger systems. The larger MCSs had a peak frequency in May while the smaller MCSs had a peak frequency in July.

Table 4.2: Distribution of MCS type (1996-1998).

\begin{tabular}{lcccccc}
\hline \hline MCS Type & April & May & June & July & August & Total \\
\hline MCC & 8 & 32 & 20 & 29 & 22 & 111 \\
PECS & 20 & 53 & 45 & 40 & 29 & 187 \\
M $\beta$ MCC & 3 & 10 & 20 & 21 & 17 & 71 \\
M $\beta$ PECS & 11 & 16 & 25 & 28 & 16 & 96 \\
Total & 42 & 111 & 110 & 118 & 84 & $\mathbf{4 6 5}$ \\
\hline
\end{tabular}

Average statistics for each MCS class can be found in Table 4.3. Obviously, the larger systems had much larger average maximum areas than the smaller systems. The PECS had the largest average maximum area at over $200,000 \mathrm{~km}^{2}$ while the smaller systems had average maximum areas under $100,000 \mathrm{~km}^{2}$. However, the extremely massive systems skew the average maximum size as shown by the large standard deviations. When the distribution of all MCSs is plotted as a function of size (see Figure 4.1), there is an exponential decrease in the number of systems when moving toward larger systems. The tail would be much longer than this, but 30 systems were left off as the largest system grew to over $800,000 \mathrm{~km}^{2}$. Even though the average maximum size of all the systems was around $160,000 \mathrm{~km}^{2}$, about $2 / 3$ of the systems were smaller than the average. Thus, it is more common to observe a system smaller than average as opposed to a system larger than average even though more systems fall into the larger MCS categories of MCCs and PECSs. 
Table 4.3: Statistics for each MCS type: means and (standard deviations).

\begin{tabular}{lccc}
\hline \hline MCS Type & $\begin{array}{c}\text { Maximum Area } \\
\left(\mathrm{km}^{2}\right)\end{array}$ & $\begin{array}{c}\text { Duration } \\
(\mathrm{h})\end{array}$ & Eccentricity \\
\hline MCC & $193,282(108,146)$ & $10.9(3.9)$ & $0.83(0.09)$ \\
PECS & $213,473(130,020)$ & $10.6(3.8)$ & $0.50(0.13)$ \\
M $\beta$ MCC & $74,696(21,540)$ & $6.1(2.2)$ & $0.84(0.08)$ \\
M $\beta$ PECS & $85,195(29,786)$ & $6.7(2.1)$ & $0.53(0.11)$ \\
All MCSs & $160,980(116,140)$ & $9.2(3.9)$ & $0.64(0.19)$ \\
\hline
\end{tabular}

The average duration of each type of MCS can also be found in Table 4.3. The larger systems persisted longer than the smaller systems as would be expected due to the nature of the duration criteria in their definitions. Given that a system is classified as a larger system or smaller system, the shape didn't appear to have much influence on the duration of the system as MCCs and PECSs had nearly identical durations, and $\mathrm{M} \beta \mathrm{MCCs}$ and $\mathrm{M} \beta \mathrm{PECSs}$ also had very similar durations. The larger systems lasted more than 10 hours on average while the smaller systems lasted more than 6 hours on average. The average lifetime of all MCSs was over 9 hours.

The average and standard deviation of the eccentricities for each type of MCS are listed in Table 4.3. The circular systems, MCCs and M $\beta$ MCCs, had very similar eccentricities, and the linear systems, PECSs and M $\beta$ PECSs, also had very similar eccentricities. The circular systems had an average eccentricity of around 0.83 with a small standard deviation as required by their definition. The linear systems had an average eccentricity around 0.50 .

The distribution of times at which these systems formed, matured, and dissipated can be found in Figure 4.2. The frequency of times at which the MCSs first 


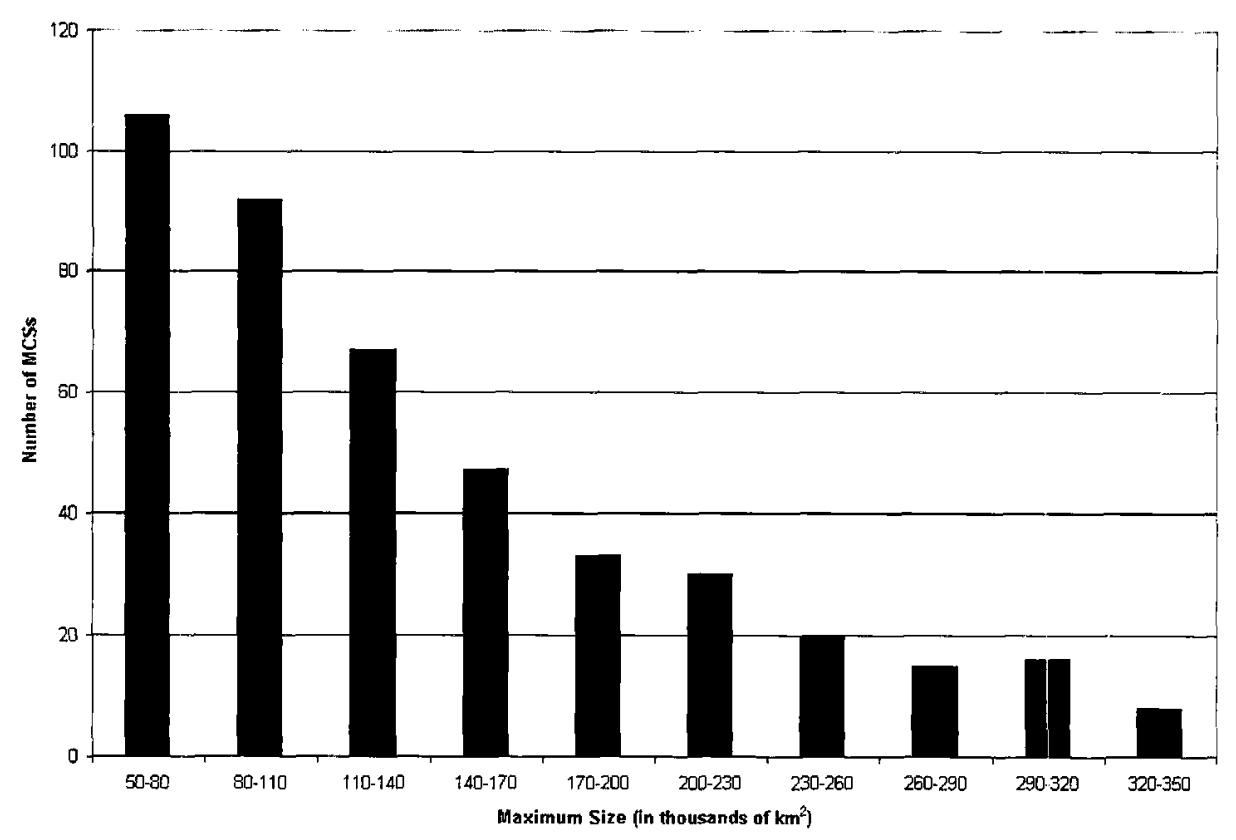

Figure 4.1: Distribution of all MCSs as a function of size.

met their definition is displayed at the front of Figure 4.2. The distribution of initiation time for the MCSs in this sample was close to normal. Nearly $60 \%$ of all MCSs initiated between $2000 \mathrm{UTC}$ and 0300 UTC. This corresponds to 3 p.m. to 10 p.m. CDT for the central United States during the warm season. Thus, these systems primarily initiated during the afternoon and evening hours. Figure 4.2 also shows the distribution of times of maximum extent for all MCSs. The times that the MCSs reached their maximum extent also produced a nearly normal distribution. About $60 \%$ of the systems reached their maximum size between 0200 UTC and 0900 UTC, or about six hours after initiation. This time frame corresponds to 9 p.m. to 4 a.m. CDT. Finally, the last set of data at the back of Figure 4.2 shows the distribution of times of termination for the MCS sample. Most of the systems dissipated between 0700 UTC and 1500 UTC (2 a.m. to 10 a.m. CDT). Consequently, a majority of the systems in this study formed in the late afternoon and evening hours, reached their 
maximum size during the night, and dissipated in the early morning hours, which is consistent with Maddox's (1980) MCC study and other MCS studies.

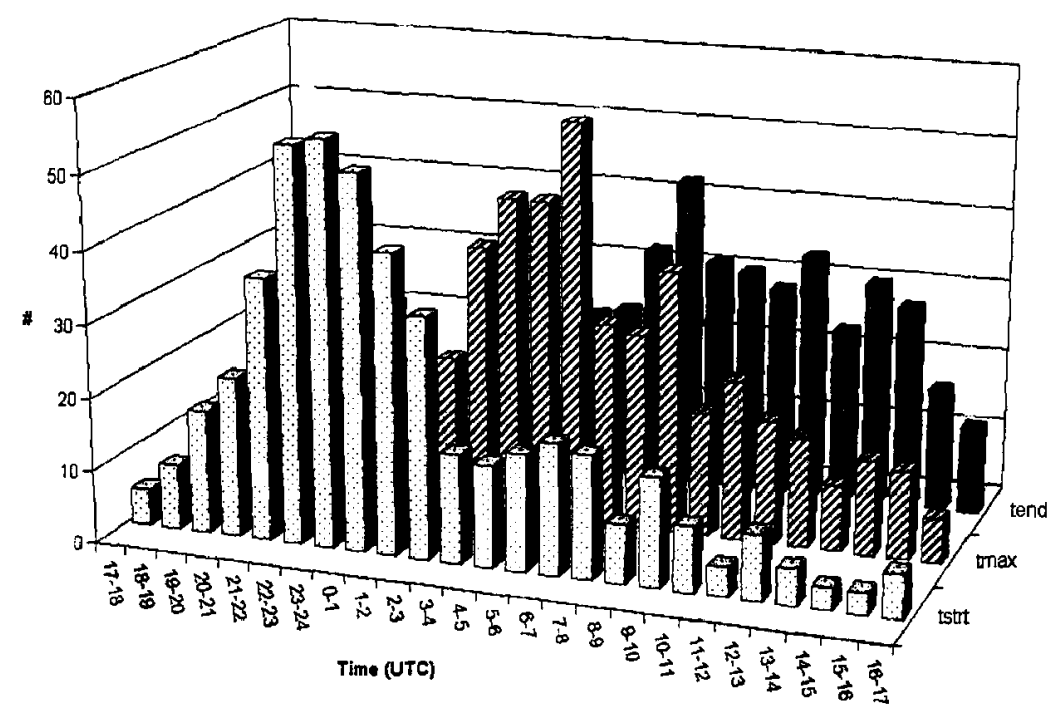

Figure 4.2: Distribution of all MCSs as a function of initiation time (tstrt), time of maximum extent (tmax), and termination time (tend).

\subsection{Examples of classes}

In order to show what some of these systems actually look like in nature, this section provides infrared satellite images for examples of each type of MCS. The duration and maximum size are also provided to help understand their lifecycle. The examples supplied in this section were selected because they were representative of their respective categories.

MCCs are probably the most striking systems due to their large size and circular shape. Figure 4.3 shows an example of a MCC as it moved across Kansas and Missouri on May 7, 1996. The top left panel was taken at 0615 UTC and shows two cloud clusters in northwest Kansas just before they merged and reached MCC status. The MCC had begun to grow by 0900 UTC and moved eastward across Kansas (top right 
panel). The MCC had just about reached its maximum area of $266,000 \mathrm{~km}^{2}$ at the $-52^{\circ} \mathrm{C}$ threshold by 1215 UTC (bottom left panel). At this time, the system was very circular with an eccentricity of 0.95 . The bottom right panel shows the system eight hours later as it dissipated to barely meet MCC criteria. Overall, the system had a duration of over 15 hours.
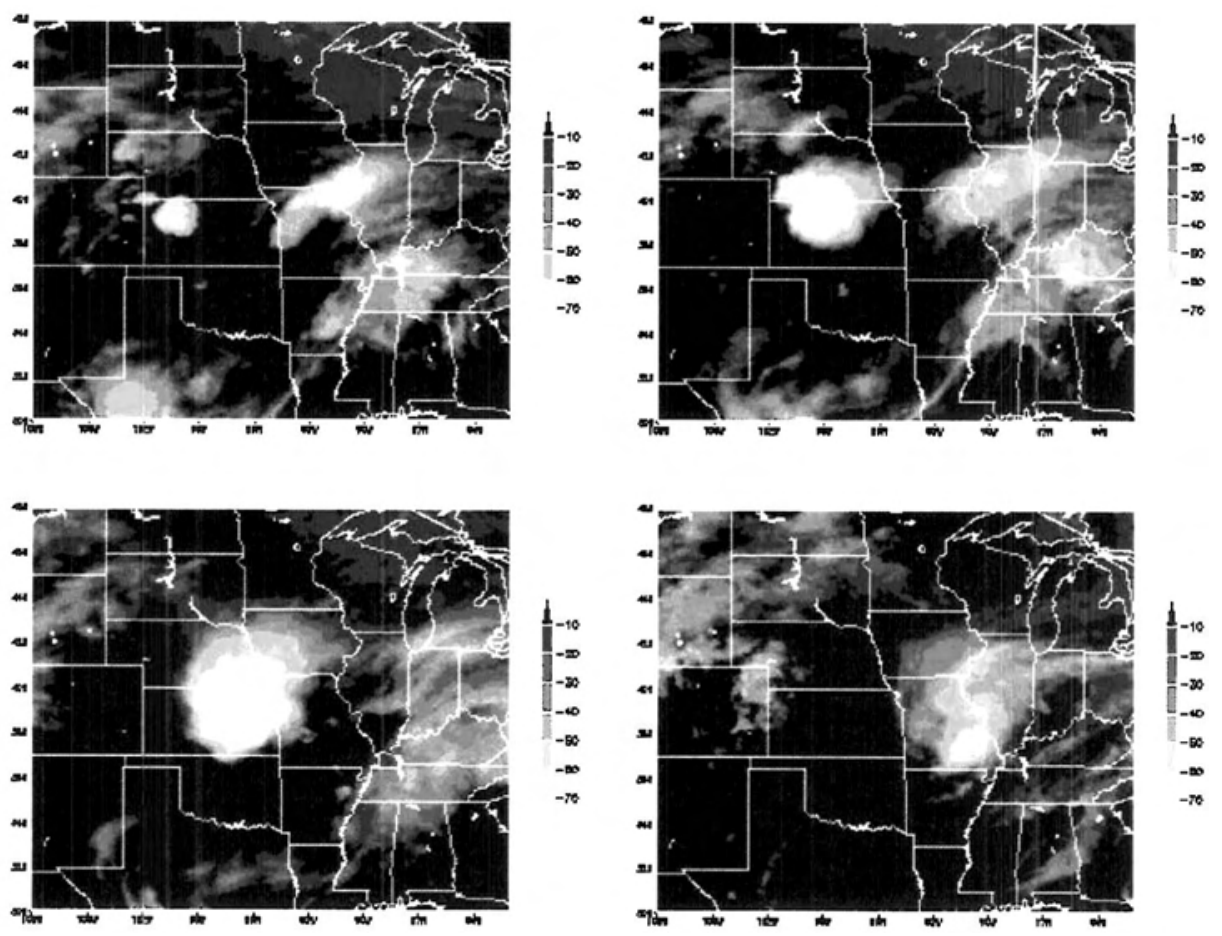

Figure 4.3: The development and dissipation of a MCC that traversed across Kansas and Missouri on May 7, 1996, as seen by infrared satellite imagery. The images are from 0615 UTC (top left), 0900 UTC (top right), 1215 UTC (bottom left), and 2015 UTC (bottom right).

Although MCCs are massive systems in their own right, PECSs can also reach very large sizes. Infrared satellite images of a PECS are shown in Figure 4.4. The system started to develop at 0045 UTC on June 20, 1998, as small cloud clusters began to grow (top left panel). By 0445 UTC (top right panel), the cloud clusters had merged over Missouri creating an oblong system that met the PECS criteria. 
The bottom left panel shows that five hours later the system had just about reached its maximum extent of $253,000 \mathrm{~km}^{2}$. By 1645 UTC (bottom right panel), the system could still be classified as a PECS, but it was well into its dissipation stage. This system persisted as a PECS for more than 17 hours without moving significantly.
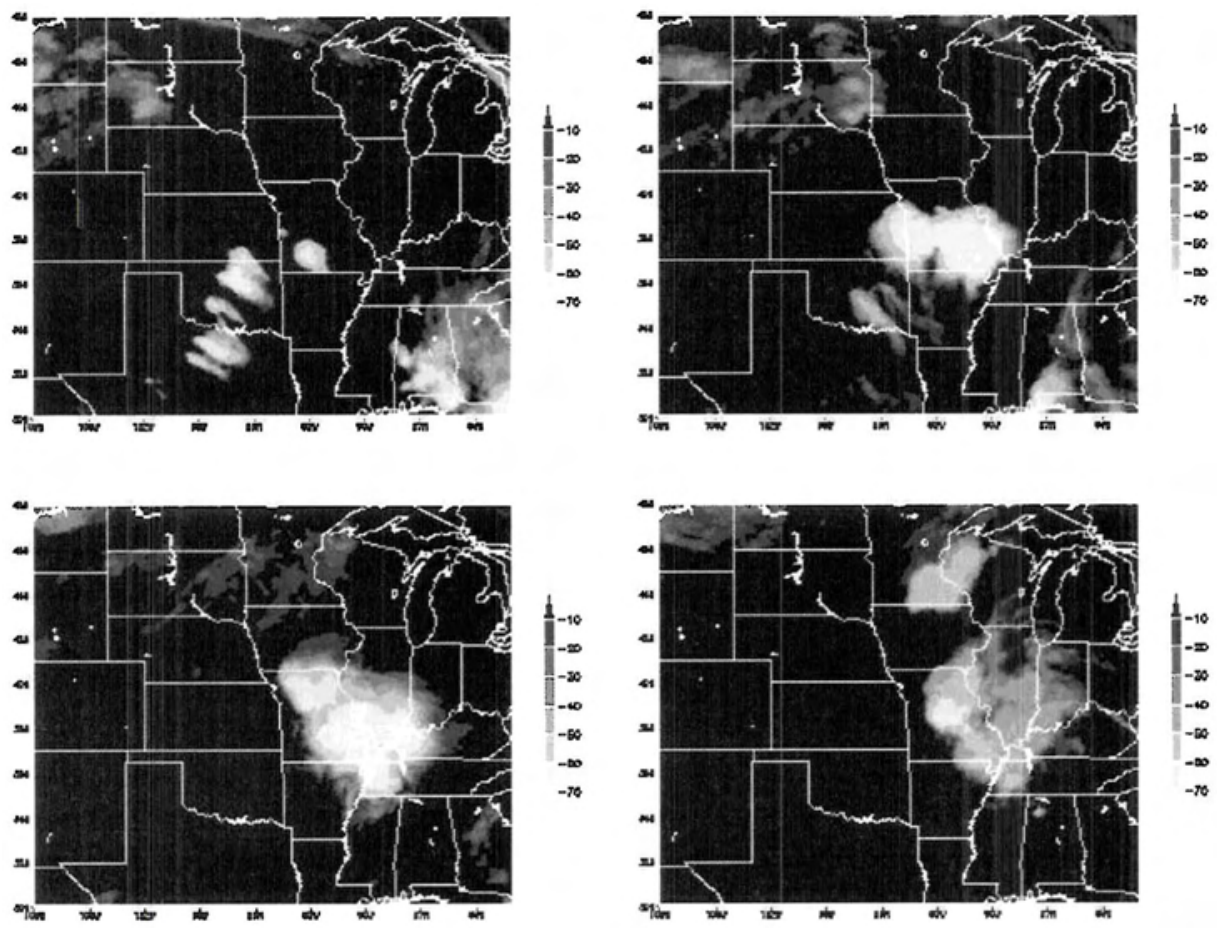

Figure 4.4: The development and dissipation of a PECS that formed over Missouri on June 20,1998, as seen by infrared satellite imagery. The images are from 0045 UTC (top left), 0445 UTC (top right), 0945 UTC (bottom left), and 1645 UTC (bottom right).

Smaller versions of MCCs, M $\beta$ MCCs, can also be very coherent and wellorganized systems as seen in this example. Figure 4.5 shows a $\mathrm{M} \beta \mathrm{MCC}$ that developed along the Oklahoma-Kansas border on July 19, 1997. The top left panel shows the system in its early stages at 0445 UTC. Just two hours later, the system had grown to meet M $\beta M C C$ criteria (top right panel). At 0845 UTC (bottom left panel), the system had reached its maximum size of $71,000 \mathrm{~km}^{2}$. The system began to dissipate 
by 1245 UTC as seen in the bottom right panel. This system was also relatively stationary and endured for over 8 hours.
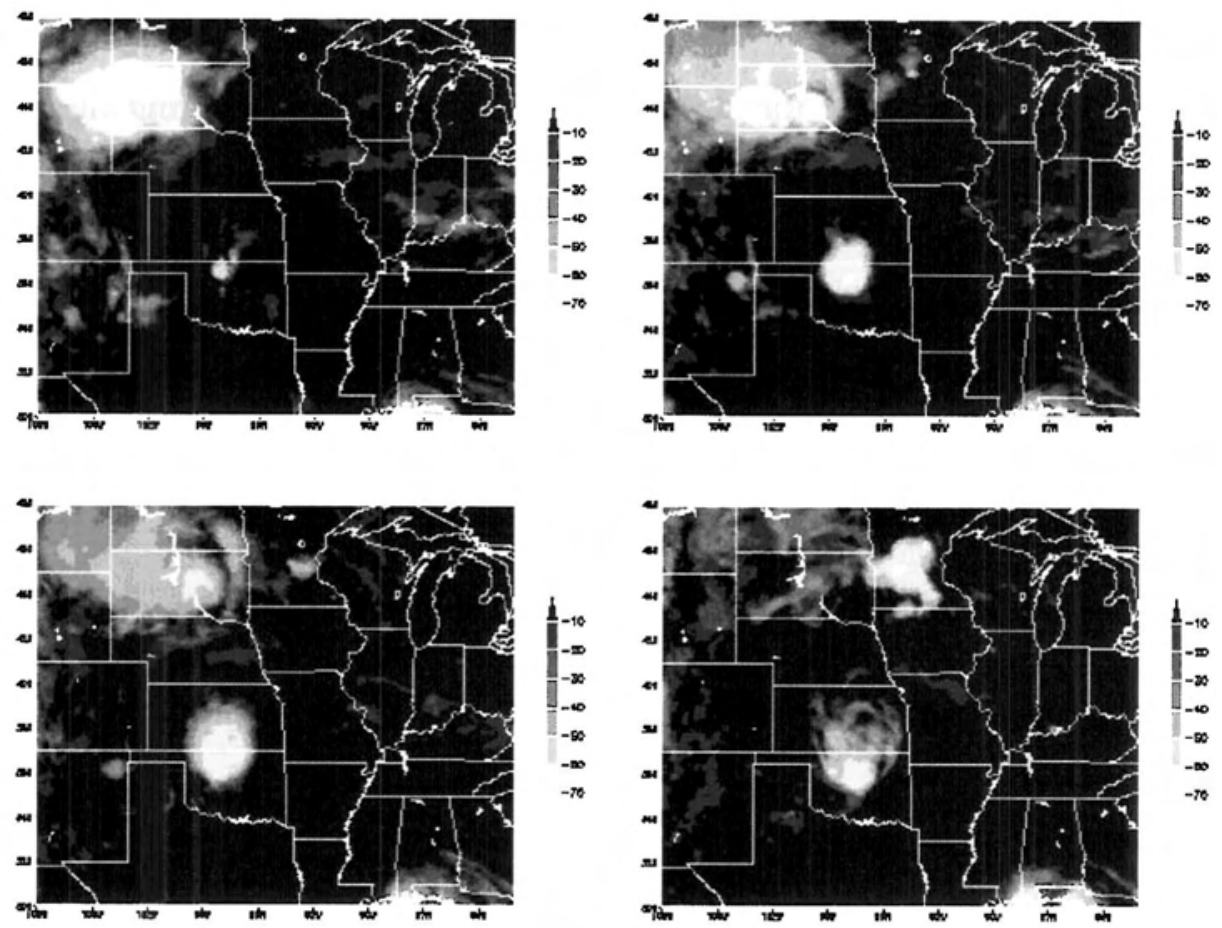

Figure 4.5: The development and dissipation of a $\mathrm{M} \beta \mathrm{MCC}$ that formed along the Oklahoma-Kansas border on July 19, 1997, as seen by infrared satellite imagery. The images are from 0445 UTC (top left), 0645 UTC (top right), 0845 UTC (bottom left), and 1245 UTC (bottom right).

The last MCS type for which an example needs to be provided is the M $\beta$ PECS category. Infrared satellite images of a M $\beta$ PECS that formed on June 19, 1996, can be found in Figure 4.6. This system began to form at 1845 UTC along the South Dakota-Minnesota border and in northern Nebraska as seen in the top left panel. Two distinct cloud clusters can be seen in the top right panel at 2000 UTC. The cloud clusters eventually merged together to form a mature, oblong system. The M $\beta$ PECS had just about reached its maximum size of $110,000 \mathrm{~km}^{2}$ by 2200 UTC (bottom left panel). At 0100 UTC on June 20, 1996 (bottom right panel), the system began to 
dissipate after almost 7 hours of existence.
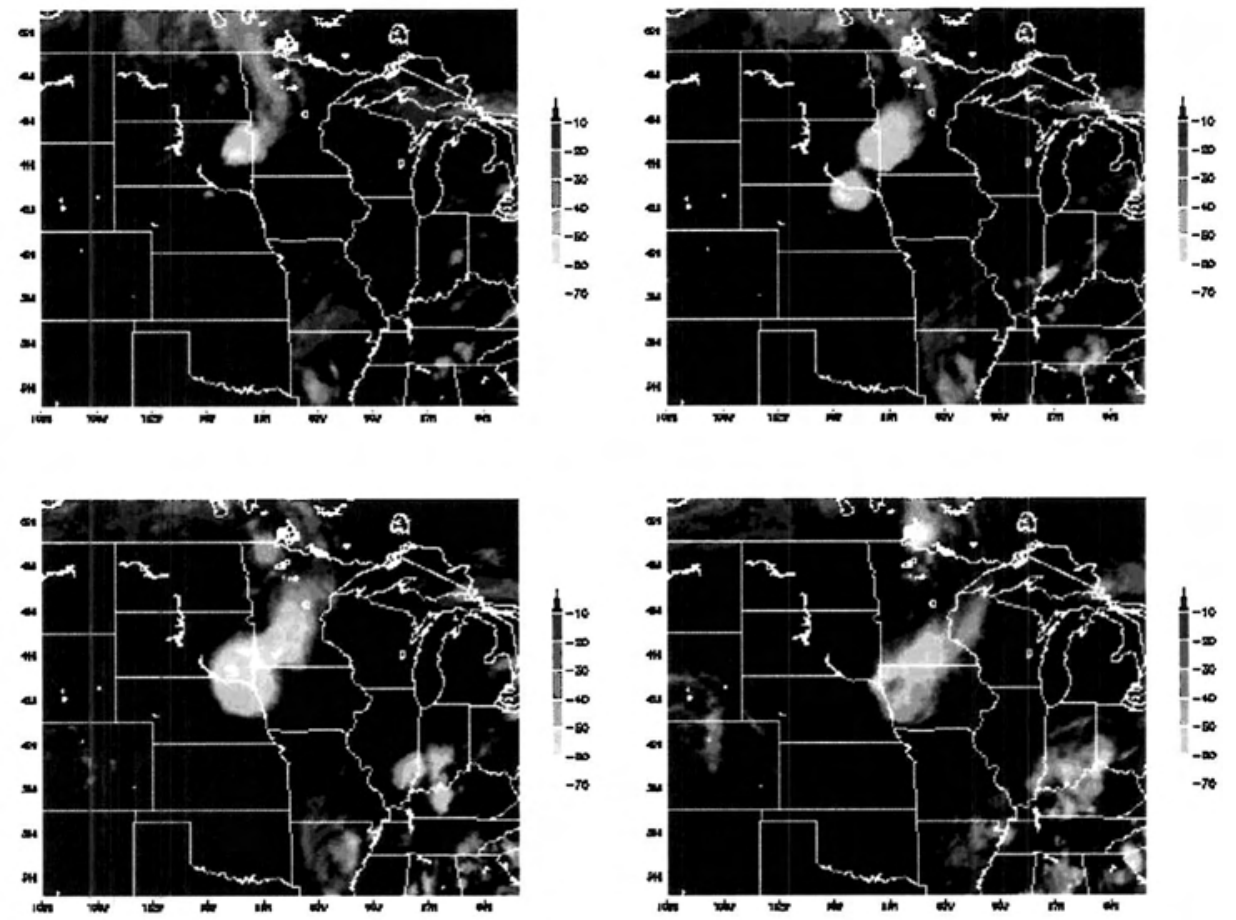

Figure 4.6: The development and dissipation of a M $\beta$ PECS that formed from Minnesota to Nebraska on June 19, 1996, as seen by infrared satellite imagery. The images are from 1845 UTC (top left), 2000 UTC (top right), 2200 UTC (bottom left), and 0100 UTC (20 June 1996) (bottom right). 


\section{Chapter 5}

\section{Radar classification of MCSs}

Similar to classifying MCSs by satellite characteristics, there have been many studies on classifying MCSs by radar characteristics (see Section 2.2). Unfortunately, the radar studies have not been well connected with one another or with the satellite classification studies. In addition, convective lines were often the only types of MCSs considered in the radar studies. As was mentioned earlier, two primary types of radar classification schemes emerged from previous studies. One scheme involves classifying mature MCSs by their arrangement of convective and stratiform precipitation. This type of classification was not of primary importance for this study, but it will be discussed in this chapter. The other radar classification scheme, which was the focus of the present study, examines the developmental stages of MCS growth. A classification scheme was devised for this study to classify a wide range of MCSs by their development and will be presented later in this chapter.

\subsection{Classification by organization}

The analysis process of each 15-minute radar field allowed time to observe the organization of each MCS. As previously mentioned, this wasn't a major priority of 
the study, so each system was examined only once to assign it to an organizational class. The systems were divided into four categories as set forth by Parker and Johnson (2000): trailing stratiform (TS), leading stratiform (LS), parallel stratiform (PS), and unclassifiable (U). In order for a system to be classified as a linear system by radar characteristics (i.e. TS, LS, or PS), it had to have a contiguous chain of convective echoes that formed a straight or curved line. Once a system was deemed to be linear, then it was classified according to the predominant arrangement of its convective and stratiform areas over its lifetime. This definition of a convective line is somewhat more restrictive than that used by Parker and Johnson (2000). Thus, it was expected for a smaller percentage of systems to meet the linear system criteria. In addition, TS systems generally have a stronger and more contiguous convective line making them more easily identifiable than LS and PS systems.

Table 5.1 shows the distribution of radar organization according to MCS satellite classification. The U and TS categories accounted for nearly $90 \%$ of the MCSs. Keep in mind that Parker and Johnson (2000) classified only linear MCSs, so basically any system without a convective line (i.e. nonlinear system) would be considered unclassifiable for this study. Thus, in looking at the totals, about half of the systems were linear and about half were nonlinear according to their radar organization. Don't forget about the possibility of a system being classified as circular according to satellite characteristics, but linear according to radar characteristics. Certainly, it appears that there is not an overwhelming relationship between the shape of the cloud shield and the existence of an underlying convective line. The larger systems (MCCs and PECSs) tended to have at least one convective line a majority of the time with PECS having the greatest percentage of convective lines (57\%). The smaller systems definitely were less likely to have a contiguous convective line (only about $40 \%$ of the 
time). The LS and PS categories combined accounted for over $20 \%$ of the lincar convective systems, which is about half of that found by Parker and Johnson (2000). However, a more lenient interpretation of a convective line might have increased this percentage.

Table 5.1: Distribution of radar organization by MCS type (1996-1998).

\begin{tabular}{lccccc}
\hline \hline MCS Type & TS & LS & PS & U & Total \\
\hline MCC & 37 & 3 & 7 & 43 & 90 \\
PECS & 66 & 9 & 10 & 64 & 149 \\
M $\beta$ MCC & 17 & 5 & 4 & 39 & 65 \\
M $\beta$ PECS & 23 & 2 & 5 & 53 & 83 \\
Total & 143 & 19 & 26 & 199 & $\mathbf{3 8 7}$ \\
\hline
\end{tabular}

Table 5.2 breaks down the classification of radar organization by month. The most striking feature of these data was the transition from a higher percentage of linear systems early in the season to a lower percentage of linear systems late in the season. From April through June, more than half of the systems contained a convective line while only about $40 \%$ of the systems were linear during July and August. This is consistent with a shift from strong synoptic and baroclinic forcing early in the convective season to weaker baroclinic (or more barotropic) forcing late in the scason.

A unique subset of radar organization that was not included in the study by Parker and Johnson (2000) is the bow echo. These systems have a curved or "bowed" convective line and often produce strong winds and downbursts (Fujita 1978). A total of 20 well-defined bow echoes were recorded for this study. These systems were equally common among the satellite classifications of MCC, PECS, and M $\beta$ MCC while only 
Table 5.2: Distribution of radar organization by month (1996-1998).

\begin{tabular}{lccccc}
\hline Month & TS & LS & PS & U & Total \\
\hline April & 14 & 2 & 4 & 16 & 36 \\
May & 40 & 3 & 6 & 47 & 96 \\
June & 44 & 4 & 7 & 42 & 97 \\
July & 27 & 9 & 4 & 53 & 93 \\
August & 18 & 1 & 5 & 41 & 65 \\
Total & 143 & 19 & 26 & 199 & $\mathbf{3 8 7}$ \\
\hline
\end{tabular}

one bow echo was classified as a M $\beta$ PECS. Nearly all of the systems formed from the merger of multiple convective clusters with the bow echo signature occurring just after the system reached full maturity. Finally, all but one bow echo had the TS arrangement with one system having the LS arrangement (see bottom left panel of Fig. 5.1).

The satellite lifecycle characteristics of the MCSs are broken down in Table 5.3 by type of radar organization. The TS archetype encompasses a wide range of systems making it the mast variable category. Nevertheless, the TS systems were statistically larger and longer-lived than the PS and LS systems. This agrees with the results of Parker and Johnson (2000) that TS systems had a mean duration almost twice that of the PS and LS systems. The results of this study are not as dramatic, but remember that they defined the duration of the systems by radar characteristics and not satellite characteristics, as was done in this study.

To provide an idea of what each category of radar organization looks like, examples are provided in Figure 5.1. These radar reflectivity images are representative examples of each category. The images chosen were taken at approximately the time 